\title{
Encoding and arousal factors in free recall of verbal and visual material'
}

STEPHEN KAPLAN, RACHEL KAPLAN, AND JEFFREY R. SAMPSON, DEPARTMENT OF PSYCHOLOGY, UNIVERSITY OF MICHIGAN, Ann Arbor, Mich. 48104

Forty male Ss were presented 24 items, half as words and half as simple line drawings with the instruction to try to remember them. Free recall was tested immediately after presentation and 30 min later. Picture recall was significantly greater than word recall $(p<.001)$. Mean GSRs based on items presented as words predicted both word and picture recall $(p<.001)$. It was suggested that the GSR findings point to a verbal encoding both for words and pictures. Since pictures appear to be coded visually as well, their double coding might provide an explanation for superior memory of these items.

Since the initial studies by Kleinsmith \& Kaplan $(1963,1964)$ on the interaction of arousal and time of recall in retention of verbal material, several interesting procedural variants have been explored. Levonian (1966) compared immediate and long-term recall for the same Ss. He found that the arousal reaction following reminisced items (those recalled only on the long-term measure) was greater than that following forgotten items (those only recalled on the short-term measure). Though Maltzman, Kantor, \& Langdon (1966) recorded galvanic skin response (GSR), their analyses are based.on a priori groupings of the stimuli. In a free recall test they found that items that were classed as high arousal using this procedure were better recalled than low arousal items for both time conditions. This finding is not contrary to the Kleinsmith and Kaplan and Levonian results, since the use of both free recall and content-based groupings are critical methodological departures from the original paradigm (Kaplan \& Kaplan, 1968). This approach raises interesting possibilities and merits further exploration.

In addition to these two directly relevant developments, another recent trend in the literature has influenced the design of this study. There appears to be growing interest in the role of nonverbal coding in the memory process. Paivio and his associates (Paivio, Yuille, \& Smythe, 1966; Smythe \& Paivio, 1968) have studied the influence of "word imagery" on recall and Turvey (1967) has obtained results pointing to the importance of a "connotative (non-acoustic) code." In a rather different context Blank, Altman, \& Bridger (1968) obtained findings that they attribute to "nonverbal representation." As to the specific form of representation, they further suggest "it seems likely that imagery may have been used."

The present study utilizes a free recall procedure following Maltzman et al and a test-retest paradigm following Levonian. It also employs both verbal and figural material to explore the possibility that the form of representation or coding may interact with arousal.

Method

Forty male undergraduate students were the Ss. Their participation partially fulfilled the introductory course requirement to serve as Ss.

The stimuli consisted of 24 items: ARROW, BALL, BOAT, BOTTLE, CAT, CIRCLE, FUNNEL, LAMP, PIPE; STAR, SUN, WINDOW, BIRD, BOOK, CANE, CUP, FISH, FLOWER, FORK, MOON, PENCIL, SQUARE, WATCH, and WHEEL. Half the Ss saw the first 12 of these as words and the remainder as pictures while the other half of the Ss saw the first 12 items as pictures and the remainder as words. The interpolation stimuli consisted of color slides. Each slide was presented for $4 \mathrm{sec}$.

After an initial slide reading READY, the $S$ was presented 24 three-slide modules. The first and third of these were color slides; the second was a typed word or simple line drawing. Four lists were used to balance order of presentation and words vs pictures.
No more than three consecutive modules contained either words only or pictures only in any of the lists.

The Ss were instructed to name the colors and not to respond to the words and drawings but to study them carefully for a later recall task. Immediately after presentation of the slides, the Ss were given paper and pencil and instructed to reproduce as accurately as possible as many items as they could recall, in any order. After $\mathbf{3 0}$ min of tasks independent of the recall situation, Ss were again asked to reproduce the critical items they could recall.

The Ss wore zinc electrodes throughout the session. Skin resistance was recorded during the slide presentation. The modified Lykken electrodes are described in Kaplan \& Fisher (1964) and the skin resistance recording set-up is described in Kaplan \& Hobart (1965).

A GSR score was computed for each $\mathrm{S}$ for each word and picture item. These were obtained by calculating the percentage decrement in skin resistance from the onset of the word or picture slide to the point of lowest resistance within a $12 \mathrm{sec}$ interval.

Results

Following Levonian's procedure, two mean GSR scores were computed for each $S$ who had at least one forgetting event and at least one reminiscence event. The mean GSR for the reminisced items was significantly greater than for the forgotten items $(t=$ $3.43, \mathrm{df}=12, \mathrm{p}<.01$ ).

The recall of pictures was significantly greater than for words $(t$ $=5.63, \mathrm{df}=39, \mathrm{p}<.001$ ). All but five of the Ss recalled at least as many pictures as words. The mean immediate recall for pictures was $47 \%$ and for words $32 \%$.

Reversals (i.e., representing a picture as a word or vice versa) were rare. Only eight of the 40 Ss showed any reversals, with five of these Ss showing one reversal apiece, and the remaining nine reversals distributed among the other three Ss. The direction of reversals was quite consistent; six Ss represented one or more

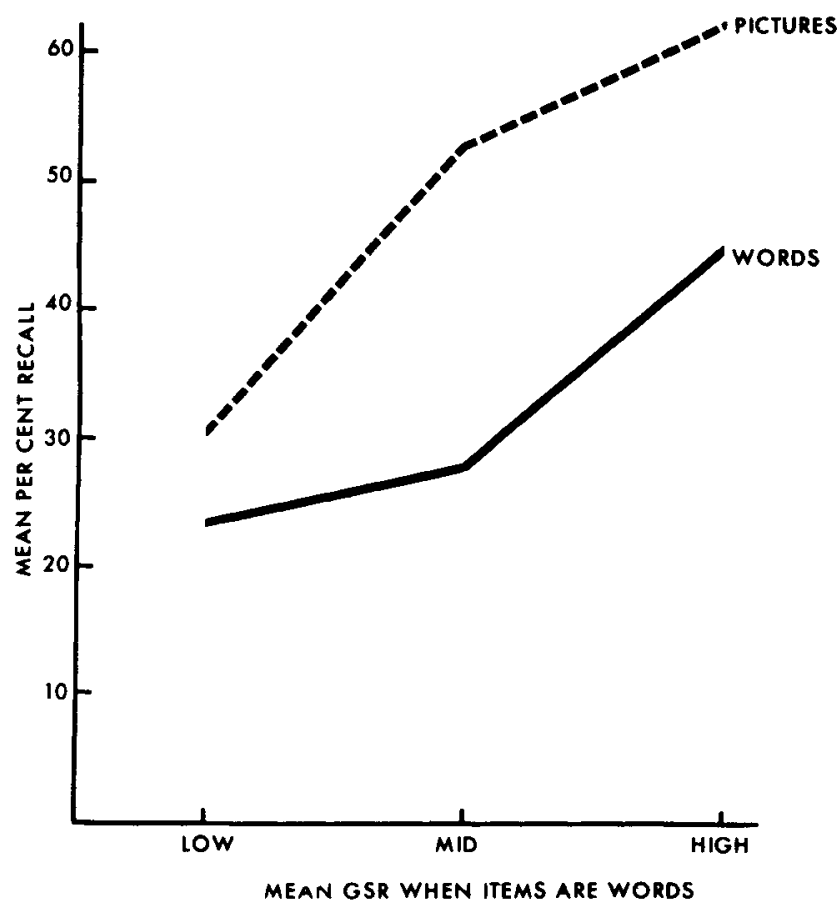

Fig. 1. Mean per cent recall of words and pictures as a function of grouping by mean GSR when the items are presented as words. 


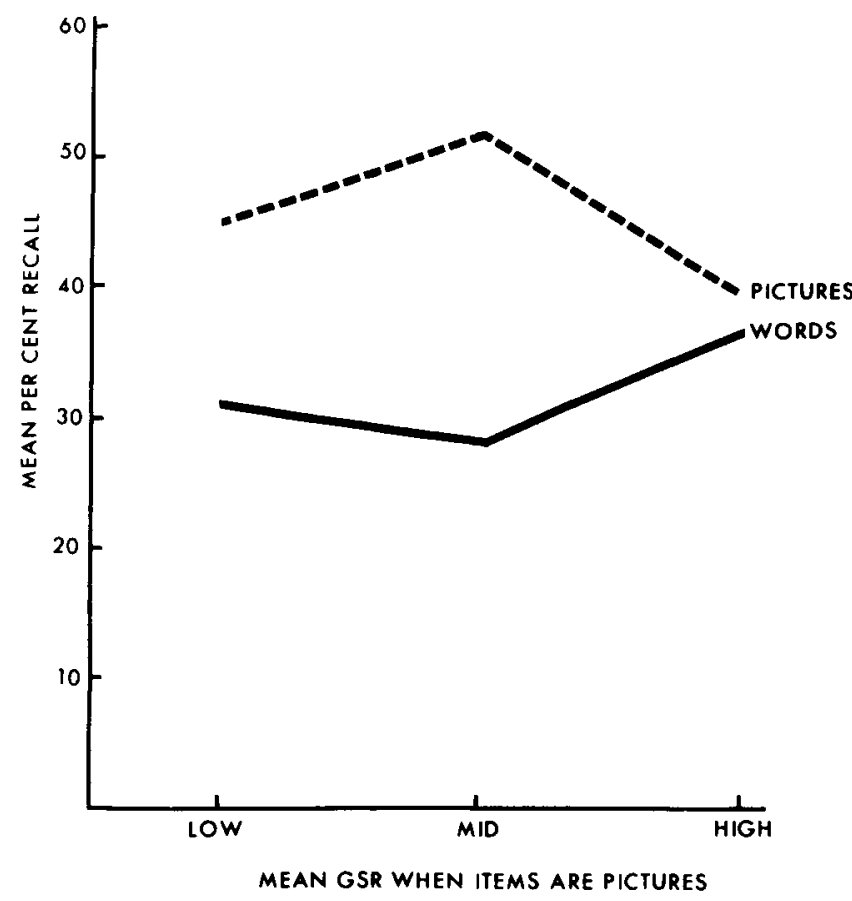

Fig. 2. Mean per cent recall of words and pictures as a function of grouping by mean GSR when the items are presented as pictures.

words as pictures and the remaining two Ss had reversals in both directions. Of the 14 reversals all but three were in the direction of words represented as pictures.

Since a given item was a word for half the Ss and a picture for half the Ss, separate mean GSRs were computed for each item as a picture and as a word. For each of these sets of values the items were divided into thirds consisting of eight items each. Figure 1 shows the mean per cent recall of words and of pictures as a function of the mean GSR when the items were presented as words. Figure 2 shows these mean recall values as a function of the mean GSR when the items were presented as pictures. The results presented in Fig. 2 are not significant $(F=$ $1.20, \mathrm{df}=2,78$ for word recall and $\mathrm{F}=2.50, \mathrm{df}=2,78$ for picture recall). When based on mean GSR to the items as words, however, both word recall and picture recall results are significant at $\mathrm{p}<$ $.001(\mathrm{~F}=9.79, \mathrm{df}=2,78$, for word recall and $\mathrm{F}=19.52$, $\mathrm{df}=$ 2,78 , for picture recall).

It should be noted that all items are used in each of these analyses although each S saw only half of these as words or as pictures. Thus, when mean GSR to items as words is used to predict picture recall, for each item half the Ss contribute the GSR and the other half the recall. In this way those Ss providing the GSR for a given item are serving as a panel of judges evaluating the item with respect to its GSR-evoking properties.

Discussion

The finding that GSRs associated with reminisced items are larger than those associated with forgotten items confirms the previous findings by Kleinsmith and Kaplan and by Levonian. In other words, an item that shows poor immediate recall and good long-term recall is associated with a larger arousal reaction than an item that is recalled only initially.

The remaining findings appear to require explanation in terms of encoding patterns. Certainly the paucity of reversals suggests that the verbal material and figural are differently encoded. The finding that the word GSR (but not the picture GSR) predicts both word and picture recall, on the other hand, suggests that both kinds of material were coded verbally, since the mean GSR to the item presumably reflects something about its encoding structure (cf. Kaplan \& Kaplan, 1968). If indeed pictures were coded differently from words and both pictures and words were coded verbally, the simplest hypothesis would seem to be that pictures are coded both verbally and visually' while words are coded only verbally. That is, at least under a set to learn when $S$ views the picture of an object, he tends to think of its name as well; when he views the name of an object, he does not tend to think of the picture or image of the object. This double coding for pictures would help explain the superior recall for pictures, and would also predict the direction of errors. If in retrieval the $S$ distinguishes pictures from words in terms of the double encoding of pictures, then if he happened to have a figural association to a word, this word would be double encoded and thus likely to be identified as a picture. The converse would not be the case since the model assumes that Ss routinely label all pictures, that is, encode them verbally as well as visually.

Thus these data point to several possibilities worthy of further research. First, the study supports the contention that verbal encoding is not the sole mode of memory storage. Second, verbal encoding is apparently quite pervasive, at least for Ss with instructions to learn. Third, words and pictures appear to be coded differently, offering a technique for further study of forms of encoding. Finally, there appears to be a special relationship between verbal encoding and GSR that merits further study. Word GSRs predicted recall not only of words, but of pictures as well.

It should be remembered that the GSR in the latter case was obtained for Ss for whom a given item was presented as a word while the recall is based on the performance of those Ss who had the item as a picture. Thus normative GSR values for objects as words could be of use in subsequent research on recall of these objects when presented as pictures.

\section{REFERENCES}

BLANK, M., ALTMAN, L. D., \& BRIDGER, W. H. Crossmodal transfer of form discrimination in preschool children. Psychon. Sci. 1968, 10, 51-52.

KAPLAN, S., \& FISHER, G. R. A modified design for the Lykken zinc electrodes. Psychophysiology, 1964, 1, 88-89.

KAPLAN, S., \& HOBART, J. L. New technique for recording skin resistance. Amer. J. med. Electron, 1965, 4, 117-120.

KAPLAN, S., \& KAPLAN, R. Arousal and memory: A comment. Psychon. Sci. 1968, 10, 291-292.

KLEINSMITH, L. J., \& KAPLAN, S. Paired-associate learning as a function of arousal and interpolated interval. J. exp. Psychol., 1963, 65, 190-193.

KLEINSMITH, L. J., \& KAPLAN, S. Interaction of arousal and recall in nonsense syllable paired-associate learning. J. exp. Psychol, 1964, 67, 124126.

LEVONIAN, E. Attention and consolidation as factors in retention. Psychon. Sci, 1966, 6, 275-276.

MALTZMAN, I., KANTOR, W., \& LANGDON, B. Immediate and delayed retention, arousal, and the orienting and defense reflexes. Psychon. Sci, $1966,6,445-446$.

PAIVIO, A., YUILLE, J. C., \& SMYTHE, P. C. Stimulus and response abstractness, imagery, and meaningfulness, and reported mediators in paired-associate learning. Canad. J. Psychol, 1966, 20, 362-377.

SMYTHE, P. C., \& PAIVIO, A. A comparison of the effectiveness of word imagery and meaningfulness in paired-associate learning of nouns. Psychon. Sci., 1968, 10, 49-50.

TURVEY, M. T. Evidence of a connotative dimension in short-term memory as a function of retention interva!. Psychon. Sci, 1967, 9, 547-548. NOTE

1. This investigation was supported in part by Research Grant MH-11599 from the National Institute of Mental Health, United States Public Health Service to SK and RK. 